\title{
ON EXPEDIENCY OF DIVIDING PUBLIC NEEDS \\ IN THE SPHERE OF PURCHASES OF GOODS, WORKS AND SERVICES INTO GENERAL AND INTRA-ORGANIZATIONAL ONES
}

\author{
Vitaliy V. Kikavets \\ Russian State University of Justice, Moscow, Russian Federation
}

Introduction: the financial support of the public interest in the sphere of procurement is inextricably linked with the needs of the state in goods, works and services. At the same time, both state and municipal purchases include, as a rule, not only public needs aimed at performing the state functions, but also the needs of the existence and functioning of the customer as the executor of the state functions. Taking this into account, the purpose of the study is to assess the subject of the author's hypothesis on the need to exclude the phrases "state and municipal needs" from the normative legal acts regulating the sphere of procurement, and enshrine at the statutory level a single general concept of "public needs", as well as mandatorily divide them into general and intra-organizational ones. Methods: the methodological framework for the research consists of the following methods of scientific knowledge: historicism, systematicity, analysis, synthesis and comparative law. The results of the analysis of the normative legal acts regulating the sphere of procurement, the doctrinal literature and real practice allowed us to establish that the budget financing provides the planned and approved customer needs for goods, works, services, which also include the functioning of the customer. The use of the concept of "needs" and their confusion under the name of "state and municipal needs", do not correspond to the meaning of "need", which is a form of realization of the state functions. The concept of "needs" is more often used, both in connection with the implementation of the will and desire of the subject, and the implementation of actions against his will and desire, when he/she is forced by external circumstances or certain forces. The concept of "needs", as a rule, assumes the presence of the subject's own will to achieve a certain goal associated with the need to ensure its existence and activity. Needs are the basis of the manifestation of the subject's interest to achieve something, and the interest itself acts as a conscious need. Needs are not always directed to the interest of the subject. Conclusions: the study revealed that in order to unify the conceptual apparatus in the sphere of procurement, it is necessary to introduce and legalize a single concept of "public needs", which will not only reflect its essence and content, but also contribute to the uniformity of its use by the state and municipal customers, state corporations and other customers involved in ensuring public needs. The division of "public needs" into general and intra-organizational ones will allow all stakeholders to clearly assess both the necessity for the declared needs and the amounts declared for funding from the budget. This, if it does not increase the efficiency of budget spending, will at least contribute to their optimization.

Key words: the public interest, public needs, general and intra-organizational needs, budget expenditures, financial support, contracting procurement.

Citation. Kikavets V.V. On Expediency of Dividing Public Needs in the Sphere of Purchases of Goods, Works and Services into General and Intra-Organizational Ones. Legal Concept, 2019, vol. 18, no. 4, pp. 83-89. (in Russian). DOI: https://doi.org/10.15688/lc.jvolsu.2019.4.11

О ЦЕЛЕСООБРАЗНОСТИ РАЗГРАНИЧЕНИЯ ПУБЛИЧНЫХ ПОТРЕБНОСТЕЙ В СФЕРЕ ЗАКУПОК ТОВАРОВ, РАБОТ И УСЛУГ НА ОБЩИЕ И ВНУТРИОРГАНИЗАЦИОННЫЕ

\section{Виталий Викторович Кикавец}




\section{ТЕОРИЯ И ПРАКТИКА ГОСУДАРСТВЕННО-ПРАВОВОГО РАЗВИТИЯ}

Введение: финансовое обеспечение публичных интересов в сфере закупок неразрывно связано с потребностями государства в товарах, работах, услугах. При этом и государственные, и муниципальные закупки включают, как правило, потребности не только публичные, направленные на выполнение функций государства, но и существования и функционирования самого заказчика как исполнителя этих функций. Целью исследования является предметная оценка авторской гипотезы о необходимости исключения из нормативных правовых актов, регулирующих сферу закупок, словосочетания «государственные и муниципальные нужды» и легального закрепления единого общего понятия «публичные потребности», а также обязательного разграничения потребностей на общие и внутриорганизационные. Методы: методологическую основу составили методы научного познания (историзм, системность, анализа, синтез) и сравнительно-правовой.Результаты: бюджетное финансирование обеспечивает запланированные и утвержденные потребности заказчика в товарах, работах, услугах, в состав которых также входит и обеспечение функционирования самого заказчика. Использование понятия «нужды» и его смешение под общим наименованием «государственные и муниципальные нужды» не соответствуют смыслу понятия «потребность», представляющего форму реализации функций государства. Понятие «нужды» чаще используется в связи и с реализаций воли и желания самого субъекта, и с осуществлением действий, которые его вынуждают выполнять внешние обстоятельства или силы. Понятие «потребности», как правило, предполагает наличие у субъекта собственной воли в достижении цели, связанной с необходимостью обеспечения его существования и деятельности. Потребности составляют основу проявления интереса у субъекта к достижению чего-либо, а сам интерес выступает как осознанная потребность. Нужды не всегда направлены на достижение интереса субъекта. Выводы: в целях унификации понятийного аппарата в сфере закупок необходимо ввести и легализовать единое понятие «публичные потребности», которое будет не только отражать свою сущность и содержание, но и способствовать единообразию его использования государственными и муниципальными заказчиками, государственными корпорациями и иными заказчиками, участвующими в обеспечении публичных потребностей. Разделение публичных потребностей на общие и внутриорганизационные позволит всем заинтересованным лицам наглядно оценить как саму необходимость в заявленных потребностях, так и суммы, заявленные к финансированию за счет бюджета. Указанное должно способствовать не только повышению эффективности расхода бюджетных средств, но и их оптимизации.

Ключевые слова: публичные интересы, публичные потребности, общие и внутриорганизационные потребности, бюджетные расходы, финансовое обеспечение, контрактная система в сфере закупок.

Цитирование. Кикавец В. В. О целесообразности разграничения публичных потребностей в сфере закупок товаров, работ и услуг на общие и внутриорганизационные // Legal Concept = Правовая парадигма. -2019. - Т. 18, № 4. - С. 83-89. - DOI: https://doi.org/10.15688/lc.jvolsu.2019.4.11

\section{Введение}

Ежегодное увеличение объема расходов бюджетных средств, реализуемых в рамках контрактной системы в сфере закупок, требует акцентированного внимания и контроля, в том числе за эффективностью указанных расходов.

В рамках норм ст. 34 Бюджетного кодекса Российской Федерации [4] (далее - БК РФ) эффективность использования бюджетных средств определяется получением заданного результата при условии достижения экономии средств бюджета и/или получения наилучшего результата в процессе реализации выделенного объема бюджетных средств. Принимая указанное во внимание, а также то, что результатом (заданным или наилучшим) является конечное удовлетворение потребностей государства в товарах, работах и услугах, полагаем необходимым раскрыть содержание понятийного аппарата, а именно - понятия «публичные потребности».

\section{Государственные нужды и публичный интерес}

Понятие «государственные нужды», под которым значились определяемые установленным порядком потребности Российской Федерации или ее субъектов в продукции для решения общенациональных проблем и задач и обеспечиваемые за счет средств бюджетов и внебюджетных источников, в начале 90-х гг. получило легальное закрепление во многих нормативных правовых актах, однако на сегодняшний день большая часть из них упразднена. В Законе № 94-Ф3 [13] употреблялось, а в Законе № 44-Ф3 [12] без раскрытия содержания используется в настоящее время понятие «государственные и муниципальные нужды». 
Из всего многообразия правовых позиций, представленных такими учеными, как Л.В. Андреева [1], О.А. Беляева [2], В.С. Гладков [6], К.В. Кичик [8], В.И. Кузнецовым [9] и др., выделяется определение государственных нужд, сформулированное В.С. Гладковым: «Это юридическая форма выражения публичного интереса, получившего в процессе плановой деятельности уполномоченных органов исполнительной власти последовательную конкретизацию до уровня потребности государства в определенных товарах, работах, услугах, в ходе удовлетворения которых осуществляется государственное управление» [6, с. 22].

Разделяя мнение ученого о публичном интересе, который проявляется в определенной форме, мы не можем согласиться, что эта форма «государственные», а ныне - «государственные или муниципальные нужды». Классификация власти на государственную и муниципальную в настоящее время оставляет спорные моменты и вопросы (сложно поставить на один уровень муниципальной власти маленькие поселки и города-миллионники). Однако с уверенностью возможно констатировать одно - оба вида власти являются публичной, соответственно, в процессе исполнения своих функций реализуют публичные интересы. Публичный интерес - это отражение публичных потребностей, поскольку у государства или муниципального образования, за редким исключением, нет своих интересов - есть только публичные.

\section{Публичные нужды и потребности}

Большинство словарей не содержит понятие «нужды». Исключением является «Толковый словарь живого великорусского языка» В. Даля, в котором под «нудой», или «нуждой», понимается «неволя, принуждение, крайнее стеснение, надобность, необходимость, недостаток во всем, крайность» [7, с. 1450-1451]. Под «потребностями» составитель понимал «расходы, издержки на какие-либо надобности» [7, с. 935]. Следовательно, потребность связана с определенными издержками, но не продиктована такой острой необходимостью, как нужда. В «Философском энциклопедическом словаре» понятие «потребность» рассматривается во взаимосвязи производства и по- требления материальных и духовных благ. При этом удовлетворение текущих потребностей неизменно приводит к образованию новых [14, c. 500]. В «Большом энциклопедическом словаре» сделан акцент на том, что осознанные обществом, социальными группами, общностями и индивидами потребности рассматриваются как их интересы [3, с. 949].

Следовательно, потребность проявляется в достижении обществом в рамках своего социально-политического, культурного и финансово-экономического развития определенных целей. В этом случае задача государства - формирование именно разумных потребностей, являющихся залогом рационального расхода бюджетных средств.

Опираясь на вышесказанное, можно констатировать следующее: понятие «потребность» шире, чем «нужда», поскольку включает последнюю. При этом наличие нужды жизненно необходимо, продиктовано природой (дышать воздухом, питаться), а потребность это результат развития общественного сознания, без которого возможно существование общества, но достаточно затруднительно (дышать свежим воздухом, горячее или калорийное питание и т. д.).

Потребности лежат в основе проявления у субъекта интереса к достижению чего-либо, а сам интерес выступает как осознанная потребность. Нужды не всегда направлены на достижение его интереса. Вместе с тем функционирование любого заказчика обеспечивается систематическим или периодическим приобретением товаров, работ и услуг. Необходимость и фактическое наличие данной потребности позволяет нам классифицировать указанные потребности на внутриорганизационные и собственные.

Слова «нужды» и «потребности» при переводе с русского на английский язык имеют единое значение - «needs», что без уяснения внутреннего смысла и содержания способствует их ошибочному пониманию как тождественных.

Принимая во внимание изложенное, полагаем необходимым рассмотреть вопрос об использовании в нормативных правовых актах, регулирующих закупки, основного и единого понятия «публичные потребности», которое возможно употреблять для всех катего- 


\section{ТЕОРИЯ И ПРАКТИКА ГОСУДАРСТВЕННО-ПРАВОВОГО РАЗВИТИЯ}

рий заказчиков: на федеральном уровне, уровне субъекта Российской Федерации и муниципальном уровне. Таким образом, категория «публичные потребности» может быть реализована в процессе обеспечения потребностей не только государственных, но и муниципальных.

\section{Разграничение публичных потребностей}

Вопрос разграничения публичных потребностей рассматривался ранее на уровне теоретических предположений соотношения «государственных нужд и собственных нужд заказчика», согласно которым большая часть ученых приняла сторону объединения всех нужд в единые - «государственные нужды» $[8$, c. 34-36].

Учитывая организационно-правовую форму юридических лиц, относимых к «категории» заказчик в рамках Закона № 44-Ф3, а также порядок их финансового обеспечения, данный вывод представляется спорным. Для обеспечения публичных потребностей органы государственной власти и казенные учреждения финансируются путем доведения лимитов бюджетных обязательств, бюджетные автономные учреждения получают субсидии на выполнение государственного (муниципального) задания, иные юридические лица - средства на осуществление капитальных вложений в объекты государственной, муниципальной собственности. При этом в данном процессе упускается тот факт, что каждый заказчик одновременно становится «получателем для себя» определенного количества товаров, объема работ или услуг.

Любой орган или учреждение создаются в целях выполнения задач и функций, для чего имеется штат работников, движимое и недвижимое имущество, на содержание, обслуживание и эксплуатацию которых выделяются средства соответствующего бюджета. Данная правовая позиция была легально закреплена в ст. 69 БК РФ (в редакции до 28.04.2007). Согласно статье среди форм предоставления бюджетных средств выделялись средства на обеспечение функционирования бюджетных учреждений и оплату заключенных ими контрактов. Основываясь на данной норме, Счетная палата Российской Федера- ции также отмечала, что бюджетные учреждения осуществляют размещение заказов для обеспечения государственных или муниципальных нужд только в случаях, когда они представляют соответствующие органы власти и осуществляют по их поручению и за их счет размещение таких заказов [11]. Напомним, что изначально Закон № 94-ФЗ не предполагал в качестве заказчиков бюджетные и автономные учреждения.

В 2007 г. в результате начала реформирования бюджетных учреждений в Закон № 94-Ф3 добавили как заказчиков бюджетные, казенные и автономные учреждения, а в ст. 69.1 БК РФ были внесены изменения, согласно которым к бюджетным ассигнованиям на оказание государственных услуг относятся ассигнования на обеспечение выполнения функций казенных учреждений и предоставление субсидий бюджетным и автономным учреждениям, включая субсидии на финансовое обеспечение выполнения ими государственного задания.

Развивая данную позицию, Минфин Российской Федерации указал, что поскольку бюджетные учреждения созданы для осуществления государственных функций и оказания государственных услуг, они не имеют собственных нужд, а значит, и правовых оснований разделять закупки на производимые для собственных и государственных нужд [10]. На наш взгляд, федеральный орган исполнительной власти не учел то, что не государство, а само бюджетное учреждение в рамках гражданских правоотношений отвечает обязательствам, в том числе и заключенным договорам, всем своим имуществом самостоятельно. Подобное смешение воедино публичных (государственных) и внутриорганизационных потребностей не соответствует эффективному расходу бюджетных средств.

\section{Внутриорганизационные публичные потребности}

Представляется уместным привести нормы Генерального соглашения по тарифам и торговле от 30.10.1947 [5], предусматривающего изъятия в части закупок госучреждениями товаров, приобретаемых для внутриорганизационных потребностей, то есть не для пос- 
B.В. Кикавец. О целесообразности разграничения публичных потребностей в сфере закупок

ледующей перепродажи или использования в производстве в коммерческих целях. К сожалению, российские органы власти не обратили должного внимание на данный документ. Следствием этого, в частности, стали масштабные проблемы, связанные с приобретением товаров, продуктов питания, в том числе скоропортящихся, бюджетными учреждениями для последующей продажи физическим лицам в рамках приносящей доход деятельности (например, в буфеты, магазины в образовательных организациях, учреждениях здравоохранения и т. д.). Ассортимент товаров и продуктов значительно сократился в силу обязанности заказчика соблюдать нормы Закона № 44-Ф3.

Приведем также другой пример. Для руководителя заказчика приобретается в собственность по итогам аукциона автомобиль бизнес-класса со снижением начальной (максимальной) цены контракта 5 млн рублей на 10 \%. Заказчик рапортует об эффективности конкурентной закупки, повлекшей эффективный расход бюджетных средств. С одной стороны, цель торгов достигнута, в том числе благодаря электронному аукциону. С другой - непонятно: какой публичный интерес достигнут в процессе пользования дорогостоящей машиной чиновником или руководителем бюджетного, казенного учреждения? Для выполнения служебных задач, должностных функций данные лица могут использовать общественный транспорт, такси, в крайнем случае - автомобили бюджетного сегмента. Аналогичные ситуации - при оплате дорогой мебели, мобильной связи, канцелярских и хозяйственных товаров, командировочных расходов и т. д. Насколько эффективны в процессе обеспечения публичного интереса подобные закупки товаров, работ, услуг для потребностей аппарата заказчика? Каким образом внутриорганизационная потребность в замене имеющейся оргтехники или мебели на новую будет способствовать результативности или эффективности деятельности заказчика?

Расходы на приведенные выше внутриорганизационные потребности заказчика «растворяются» в общей массе бюджетных средств, выделяемых на оплату товаров, работ, услуг для публичных потребностей в целом. Зачастую расходы на содержание аппарата заказчика превышают суммы, предназначенные на обеспечение публичного интереса.

\section{Результаты}

Фактическое смешение общих и внутриорганизационных публичных потребностей привело к тому, что заказчики под формулировкой «государственные и муниципальные нужды» стали осуществлять закупки дорогих машин, строительство огромных дорогих зданий, требующих в последствии внушительных затрат на обслуживание и эксплуатацию («дворцы» Пенсионного фонда России и т. д.). В качестве противодействия подобным «законным» действиям заказчиков было введено нормирование закупок определенных товаров и услуг для разных категорий чиновников. Подобная новация, как, впрочем, и многие другие новшества правового регулирования контрактной системы в сфере закупок, не в полной мере способствовала достижению поставленных целей, поскольку реализуется преимущественно внутренними локальными актами заказчика и не соотносится с реальными потребностями общества (публичным интересом). Вместе с тем акцент законодателя на необходимости нормирования в сфере закупок доказывает наличие внутриорганизационных потребностей заказчика, которые не следует смешивать и отождествлять с общими публичными потребностями.

Не устранились проблемы и с реализацией общих публичных потребностей. Например, ежегодное увеличение расходов на благоустройство г. Москвы, в результате которого встречается неоднократная замена не так давно установленных бордюрного камня или тротуарной плитки на новые образцы.

Раздельный учет финансирования общих и внутриорганизационных публичных потребностей заказчика способен наглядно показать эффективность не только государственного или муниципального управления, но и расхода бюджетных средств, направленных на выполнение функций государства, а также существование и функционирование самого заказчика как исполнителя функций государства.

\section{Выводы}

В заключении отметим, что эффективности расхода бюджетных средств возможно достичь исключительно продуманным правовым регулированием сферы закупок в соот- 


\section{ТЕОРИЯ И ПРАКТИКА ГОСУДАРСТВЕННО-ПРАВОВОГО РАЗВИТИЯ}

ветствии с ясным и понятным для всех без исключения целеполаганием и концепцией развития. Для этого вместо использования словосочетаний «государственные и муниципальные нужды» в обязательном порядке следует легально закрепить единое понятие «публичные потребности» с обязательным выделением в их составе общих и внутриорганизационных потребностей заказчика. Публичные потребности предлагаем определить как форму реализации публичного интереса в товарах, работах, услугах за счет бюджетных средств и внебюджетных источников.

Указанное позволит не только разделить государственные и муниципальные закупки, сохраняя единые принципы и методы правового регулирования, но и оптимизировать финансовое обеспечение внутриорганизационных потребностей, в том числе сократить нормы потребления, устанавливаемые во многом без учета общественного мнения - основной составляющей публичного интереса. Кроме того, это поспособствует повышению эффективности расхода бюджетных средств путем не только экономии и получения необходимого результата по каждому направлению, но и контроля соотношения расходов на общие и внутриорганизационные публичные потребности. Таким образом, значительная часть бюджетного финансирования будет направлена на реальное удовлетворение публичного интереса с помощью финансирования непосредственно общих публичных, а не внутриорганизационных потребностей заказчика.

Полагаем необходимым рассмотреть вопрос о внесении изменений в статью 34 БК РФ, согласно которым эффективность использования бюджетных средств следует определять, как своевременное и всестороннее обеспечение участником бюджетного процесса в рамках его бюджетных полномочий общих и внутриорганизационных публичных потребностей с использованием наименьшего и/или определенного объема бюджетных средств.

\section{СПИСОК ЛИТЕРАТУРЫ}

1. Андреева, Л. В. Закупки товаров для федеральных государственных нужд: правовое ре- гулирование / Л. В. Андреева. - М. : Волтерс Клувер, 2009. - $191 \mathrm{c}$.

2. Беляева, О. А. Торги: основы теории и проблемы практики : монография / О. А. Беляева. М. : Ин-т законодательства и сравнит. правоведения при Правительстве РФ : Инфра-М, 2015. - 250 с.

3. Большой энциклопедический словарь. 2-е изд., перераб. и доп. - М. : Большая Российская энциклопедия ; СПб. : Норинт, 2000. - 1456 с. : ил.

4. Бюджетный кодекс Российской Федерации от 31.07.1998 № 145-Ф3 . - Доступ из справ.-правовой системы «КонсультантПлюс».

5. Генеральное соглашение по тарифам и торговле (ГАТТ 1947). - Доступ из справ.-правовой системы «КонсультантПлюс».

6. Гладков, В. С. Государственный заказ в сфеpe государственного управления экономикой : дис. ... канд. юрид. наук / Гладков Владимир Станиславович. - Ростов н/Д, 2008. -27 с.

7. Даль, В. И. Толковый словарь живого великорусского языка : в 4 т / В. И. Даль. - М. : Прогресс : Универс, 1994. - Т. 2: И-О. -912 с. ; Т. 3: П-Р. -912 с.

8. Кичик, К. В. Государственный (муниципальный) заказ России: правовые проблемы формирования, размещения и исполнения: монография / К.В. Кичик. - М. : Юстицинформ, 2012. -260 с.

9. Кузнецов, В. И. Правовое регулирование института государственного заказа: дис. ... канд. юрид. наук / Кузнецов Владимир Иванович. - М., 2005.- 188 c

10. Письмо Минфина РФ от 06.04.2007 № 0213-10/833. - Доступ из справ.-правовой системы «КонсультантПлюс».

11. Письмо Счетной палаты РФ от 04.12.2006 № 01-1658/15-08. - Доступ из информ.-правового портала «Гарант.ру».

12. Федеральный закон от 05.04.2013 № 44-Ф3 «О контрактной системе в сфере закупок товаров, работ, услуг для обеспечения государственных и муниципальных нужд». - Доступ из справ.-правовой системы «КонсультантПлюс».

13. Федеральный закон от 21.07.2005 № 94-Ф3 «О размещении заказов на поставки товаров, выполнение работ и оказание услуг для государственных и муниципальных нужд» (утратил силу с 01.01.2014). - Доступ из справ.-правовой системы «КонсультантПлюс».

14. Философский энциклопедический словарь / редкол.: С. С. Аверинцев [и др.]. - 2-е изд. - М. : Сов. энцикл., 1989. -815 с.

\section{REFERENCES}

1. Andreeva L.V. Zakupki tovarov dlya federalnykh gosudarstvennykh nuzhd: pravovoe 
regulirovanie [Procurement of Goods for Federal State Needs: Legal Regulation]. Moscow, Volters Kluver Publ., 2009. $191 \mathrm{p}$.

2. Belyaeva O.A. Torgi: osnovy teorii i problemy praktiki : monografiya [Trades: Fundamentals of Theory and Problems of Practice. Monograph]. Moscow, Institut zakonodatelstva i sravnitelnogo pravovedeniya pri Pravitelstve RF Publ., Infra-M Publ., 2015. 250 p.

3. Bolshoy entsiklopedicheskiy slovar [A Large Encyclopedic Dictionary]. $2^{\text {nd }}$ ed., rev. and ad. Moscow, Bolshaya Rossiyskaya entsiklopediya Publ.; Saint Petersburg, Norint Publ., 2000. 1456 p.

4. Byudzhetnyy kodeks Rossiyskoy Federatsii ot 31.07.1998 № 145-FZ [The Budget Code of the Russian Federation]. Access from Reference Legal System "KonsultantPlus".

5. Generalnoe soglashenie po tarifam i torgovle (GATT 1947) [General Agreementon Tariffsand Trade (GATT 1947)]. Access from Reference Legal System "KonsultantPlus".

6. Gladkov V.S. Gosudarstvennyy zakaz v sfere gosudarstvennogo upravleniya ekonomikoy: dis.... kand. yurid. nauk [State Order in the Field of Public Administration of the Economy. Cand. jurid. sci. diss.]. Rostov-on-Don, 2008. 27 p.

7. Dahl V.I. Tolkovyy slovar zhivogo velikorusskogo yazyka : v 4 t. [Explanatory Dictionary of the Living Great Russian Language: I-O]. Moscow, Progress Publ., Univers Publ., 1994, vol. 2:I-O. 912 p.; vol. 3: P-R. 912 p.

8 Kichik K.V. Gosudarstvennyy (munitsipalnyy) zakaz Rossii: pravovye problemy formirovaniya, razmeshcheniya i ispolneniya : monografiya [State
(Municipal) Order of Russia: Legal Problems of Formation, Placement and Execution. Monograph]. Moscow, Yustitsinform, 2012. 260 p.

10. Kuznetsov V.I. Pravovoe regulirovanie instituta gosudarstvennogo zakaza: dis. ... kand. yurid. nauk [Legal Regulation of the State Order of the Institute. Cand. jurid. sci. diss.]. Moscow, 2005. $188 \mathrm{p}$.

10. Pismo Minfina RF ot 06.04.2007 № 02-1310/833 [Letter of the Ministry of Finance of the Russian Federation]. Access from Reference Legal System "KonsultantPlus".

11. Pismo Schetnoy palaty RF ot 04.12.2006 № 01-1658/15-08 [Letter of the Accounts Chamber of the Russian Federation]. Access from "Garant" Informational and Legal Web Portal.

12. Federalnyy zakon «O kontraktnoy sisteme $v$ sfere zakupok tovarov, rabot, uslug dlya obespecheniya gosudarstvennykh $i$ munitsipalnykh nuzhd» ot 05.04.2013 № 44-FZ [Federal Law “On Contract System in the Procurement of Goods, Works and Services for State and Municipal Needs" of April 5, 2013 No. 44-FL]. Access from Reference Legal System "KonsultantPlus".

13. Federalnyy zakon "O razmeshchenii zakazov na postavki tovarov, vypolnenie rabot, okazanie uslug dlya gosudarstvennykh $i$ munitsipalnykh nuzhd» ot 21.07.2005 № 94-FZ [The Federal law “On Placing Orders for Goods, Works and Services for State and Municipal Needs" of July 21, 2005 no. 94-FL]. Access from Reference Legal System "KonsultantPlus".

14. Averincev S.S. et al. eds. Filosofskiy entsiklopedicheskiy slovar [Philosophical Encyclopedic Dictionary]. ${ }^{\text {nd }}$ ed. Moscow, Sovetskaya Entsiklopediya Publ., 1989. 815 p.

\section{Information about the Author}

Vitaliy V. Kikavets, Candidate of Sciences (Jurisprudence), Associate Professor, Department of Financial Law, Russian State University of Justice, Novocheremushkinskaya St., 69, 117418 Moscow, Russian Federation, viking0071@mail.ru, finpravo@rsuj.ru, https://orcid.org/0000-0002-7931-8497

\section{Информация об авторе}

Виталий Викторович Кикавец, кандидат юридических наук, доцент кафедры финансового права, Российский государственный университет правосудия, ул. Новочеремушкинская, 69, 117418 г. Москва, Российская Федерация, viking0071@mail.ru, finpravo@rsuj.ru, https://orcid.org/0000-0002-7931-8497 